\title{
Analisis Swot Pengembangan Kawasan Wisata Telaga Ngebel Di Kabupaten Ponorogo
}

\author{
Muhammad Imron \\ Program Studi Manajemen, Universitas Merdeka Madiun, Jl. Serayu No.79, Madiun, 63133 \\ E-mail: ron_imro@yahoo.com
}

\begin{abstract}
The development of tourist areas is directed as a mainstay sector to boost economic growth, increase local revenues, empower the economy of the community, expand employment and increase the introduction and marketing of typical tourism areas. Ngebel Lake is a natural lake located in District Ngebel, Ponorogo Regency which has a stunning natural scenery with the condition is still natural, save a million potential to be developed. Development of Ngebel Lake tourism area should be planned thoroughly and use appropriate strategies in order to obtain optimal benefits for the community. The objectives of this research are: 1) to analyze the condition of external factors including opportunities and threats, 2) to analyze the condition of internal factors including strengths and weaknesses, appropriate for the development of tourism area Ngebel Lake using SWOT Analysis. Based on SWOT analysis, Telaga Ngebel tourism area has an external opportunity as well as an enormous internal strength to be developed. Result of internal and external matrix (IE), hence alternative of appropriate strategy to develop tourist area of Telaga Ngebel is SO Strategy (Strenght-Opportunity) that is a strategy chosen by using strength to utilize or seize opportunity. Implementation of the strategy is done through the development of tourism products, market development and market penetration. Important policies need to be taken, such as improving road infrastructure, developing tourism products, promoting promotion, providing souvenir shop area, handicraft and food, providing street lighting, improving hygiene and waste handling and cooperating with various parties including investors.
\end{abstract}

Keywords - : strengths; weaknesses; opportunities; threats; development.

\section{PENDAHULUAN}

Dalam rangka meningkatkan daya saing wisata, pemerintah daerah membuat rumusan strategi kebijakan yang dapat digunakan sebagai roadmap dalam membangun sebuah obyek wisata agar berdaya saing. Kebijakan seyogyanya bersandar pada kondisi semua aspek di kawasan wisata. Beberapa faktor yang dipertimbangkan dalam membuat kebijakan yang tepat antara lain: pengunjung sebagai konsumen, untuk melihat bagaimana tingkat kepuasannya, masyarakat sekitar sebagai pelaku sekaligus pihak yang terdampak oleh kegiatan wisata, hasil evaluasi kebijakan sebelumnya sudahkah memberikan kontribusi, dan apa ukuran keberhasilan dari kebijakan yang telah dilakukan.

Semua faktor tersebut harus dikaji oleh pemerintah daerah sehingga dapat dirumuskan strategi yang tepat, efektif dan efisien dalam meningkatkan daya saing sebuah kawasan wisata. Kawasan wisata yang mengandalkan potensi alam harus dikemas dalam sebuah paket pengalaman yang menyenangkan dan membekas bagi pengunjung sehingga akan menimbulkan minat untuk berkunjung kembali di obyek wisata tersebut.

Semua pihak berperan dalam meingkatkan daya saing wisata, masyarakat di sekitar kawasan, pemangku kepentingan, dan manajemen harus bekerja sama membuat suasana yang menarik dan tidak membosankan bagi pengunjung. Penataan lokasi dan perbaikan infrastruktur sangat berperan penting. Begitu juga kebersihan dan pelayanan menjadi kunci keberhasilan.

Di satu sisi, peningkatan kunjungan wisatawan terhadap kawasan wisata Telaga Ngebel juga memberikan dampak yang tidak kalah penting terhadap peningkatan kesejahteraan masyarakat sekitar. Dengan meningkatnya wisatawan, maka berpotensi menambah pendapatan masyarakat dengan menyediakan produk-produk serta jasa yang dibutuhkan wisatawan saat berkunjung di Telaga Ngebel.

Saat ini yang sudah tersedia adalah sarana umum dan unit pertokoan serta rumah makan yang menawarkan masakan khas Ngebel. Namun, dari sisi jasa penginapan masih belum tersedia secara optimal. Selain itu, masyarakat masih berpeluang menawarkan jasa-jasa lain untuk wisatawan misalnya: jasa agrowisata kunjungan ke kebun buah, jasa ojek, jasa dokumentasi dan sebagainya.

Analisis SWOT digunakan sebagai metode dalam penelitian ini karena memiliki banyak keunggulan dibandingkan nalisis yang lain yaitu dengan Analisis SWOT maka dapat diketahui situasi objek wisata dengan mengidentifikasi faktor eksternal dan faktor internal yang berpengaruh pada objek wisata, yaitu menganalisis peluang dan kekuatan yang dimiliki untuk menentukan rencana masa depan dan mengatasi kelemahan dan ancaman dengan cara rencana perbaikan.

Menurut Rangkuti (2005), Analisis SWOT merupakan suatu identifikasi berbagai faktor secara sistematis untuk merumuskan strategi perusahaan. Analisis ini didasarkan pada logika yang dapat memaksimalkan kekuatan (strengths) dan peluang (opportunities), dan secara bersamaan dapat meminimalisir kelemahan (weaknesses) dan ancaman (threats). Proses 


\section{Website : http://ekomaks.unmermadiun.ac.id/index.php/ekomaks}

pengambilan keputusan strategis selalu berkaitan dengan pengembangan misi, tujuan, strategi, dan kebijakan perusahaan. Beberapa penelitian pernah dilakukan di beberapa daerah wisata menggunakan SWOT antara lain penelitian yang dilakukan oleh Dodi Widiyanto,et al (2008) di Desa Wisata Ketingan, Penelitian oleh Moch. Prihatna Sobari, et.al (2006) di Wisata Bahari Pantai Kalianda Resort, Kabupaten Lampung Selatan, dan Dewi Ayu Maharani (2009) di objek wisata Umbul Sidomukti, Kabupaten Semarang, namun penelitian sejenis belum pernah dilakukan di kawasan wisata Telaga Ngebel. Strategi pengembangan lebih lanjut untuk menarik wisatawan berkunjung di Telaga Ngebel mutlak diperlukan dalam rangka pengembangan sektor pariwisata di Jawa Timur.

\section{TINJAUAN PUSTAKA}

\section{A. Kawasan Wisata}

Kawasan wisata adalah wilayah yang memiliki fungsi utama lindung atau budidaya (Undang-undang Nomor 26 Tahun 2007 tentang Penataan Ruang). Lebih lanjut dalam regulasi tersebut dijelaskan maksud daripada wilayah adalah ruang yang merupakan kesatuan geografis beserta segenap unsur terkait yang batas dan sistemnya ditentukan berdasarkan aspek administratif dan/atau aspek fungsional. Adisasmita, 2007 (dalam Ilyas, 2009) mencoba menjelaskan maksud dari kawasan wisata dengan menelaah kedua komponen tersebut. Kawasan adalah bentangan permukaan (alam) dengan batasbatas dan sistemnya ditentukan berdasarkan aspek fungsional. Kawasan memiliki fungsi tertentu (misalnya kawasan lindung, kawasan budidaya, kawasan pesisir pantai, kawasan pariwisata, dan lainlain). Wisata berarti perjalanan atau bepergian. Jadi kawasan wisata dalah bentangan permukaan yang dikunjungi atau didatangi oleh orang banyak (wisatawan) karena kawasan tersebut memiliki obyek wisata yang menarik.

\section{B. Analisis SWOT}

Rangkuti (2005: 18) menjelaskan bahwa analisis SWOT adalah identifikasi berbagai faktor secara sistematis untuk merumuskan strategi perusahaan. Analisis ini didasarkan pada logika yang dapat memaksimalkan kekuatan (strengths) dan peluang (opportunities), namun secara bersamaan dapat meminimalkan kelemahan (weaknesses) dan ancaman (threats). Proses pengambilan keputusan strategi selalu berkaitan dengan pengembangan misi, tujuan, strategi dan kebijakan perusahaan. Dengan demikian, perencanaan strategi harus menganalisa faktor-faktor strategi perusahaan (kekuatan, kelemahan, peluang dan ancaman) dalam kondisi yang saat ini. Analisis SWOT membandingkan antara faktor eksternal peluang (opportunities) dan ancaman (threats) dengan faktor internal kekuatan (strengths) dan kelemahan (weaknesses). Untuk menganalisis secara lebih dalam tentang SWOT, maka perlu dilihat faktor eksternal dan internal sebagai bagian penting dalam analisis, yaitu:

\section{Faktor eksternal}

Faktor eksternal ini mempengaruhi terbentuknya opportunities and threats $(\mathrm{O}$ dan $\mathrm{T})$. Dimana faktor ini menyangkut kondisi-kondisi yang terjadi di luar perusahaan yang mempengaruhi dalam pembuatan keputusan perusahaan. Faktor ini mencakup lingkungan bisnis makro, ekonomi, politik, hukum, teknologi, kependudukan, dan faktor budaya.

\section{Faktor internal}

Faktor internal ini mempengaruhi terbentuknya (strengths) and weaknesses (S dan W). Dimana faktor ini berkaitan dengan kondisi yang terjadi dalam perusahaan, yang mana ini turut mempengaruhi terbentuknya pembuatan keputusan (decision making) perusahaan. Faktor internal ini meliputi semua macam manajemen fungsional : pemasaran, keuangan, operasi, sumberdaya manusia, penelitian dan pengembangan, sistem informasi manajemen, corporate culture.

\section{Cara Menentukan Strategi}

Menurut Fred R. David (2002), teknik perumusan strategi yang penting dapat diintegrasikan ke dalam kerangka kerja pengambilan keputusan tiga tahap. Alat yang disajikan dalam kerangka kerja ini dapat digunakan untuk semua ukuran dan tipe organisasi dan dapat membantu penyusun strategi mengidentifikasi dan memilih strategi. 
Website : http://ekomaks.unmermadiun.ac.id/index.php/ekomaks

Gambar 1. Kerangka Kerja Analitis Untuk Perumusan Strategi

\begin{tabular}{|c|c|c|c|}
\hline \multicolumn{4}{|c|}{ TAHAP 1 : TAHAP INPUT (INPUT STAGE) } \\
\hline $\begin{array}{l}\text { Matriks Evaluasi } \\
\text { Faktor Eksternal } \\
\text { (External Factor } \\
\text { Evaluation -EFE) }\end{array}$ & $\begin{array}{l}\text { Matriks Profil Kompetitif } \\
\text { ( Competitive Profile } \\
\text { Matrix-CPM) }\end{array}$ & \multicolumn{2}{|c|}{$\begin{array}{l}\text { Matriks Evaluasi Faktor } \\
\text { Internal ( Internal Factor } \\
\text { Evaluation (IFE) }\end{array}$} \\
\hline \multicolumn{4}{|l|}{ 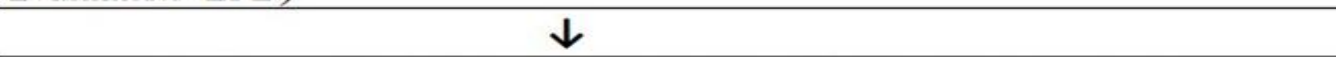 } \\
\hline \multicolumn{4}{|c|}{ TAHAP 2 : TAHAP PENCOCOKAN (MATCHING STAGE) } \\
\hline $\begin{array}{l}\text { Matriks SWOT } \\
\text { (Strength- } \\
\text { Weakness- } \\
\text { Opportunities- } \\
\text { Threats) }\end{array}$ & $\begin{array}{l}\text { Matriks SPACE } \\
\text { (Strategic Position } \\
\text { and Action Evaluation) }\end{array}$ & $\begin{array}{l}\text { Matriks BCG } \\
\text { (Boston } \\
\text { Consulting Group) }\end{array}$ & $\begin{array}{l}\text { Matriks } \\
\text { IE } \\
\text { (Internal- } \\
\text { Eksternal) }\end{array}$ \\
\hline \multicolumn{4}{|c|}{$\downarrow$} \\
\hline \multicolumn{4}{|c|}{ TAHAP 3 : TAHAP KEPUTUSAN ( DECISION STAGE) } \\
\hline \multicolumn{4}{|c|}{$\begin{array}{c}\text { Matriks Perencanaan Strategis Kuantitatif } \\
\text { ( Quantitative Strategic Planning Matrix- QSPM) }\end{array}$} \\
\hline
\end{tabular}

\section{Penjelasan :}

\section{Tahap 1 :}

Terdiri dari tiga matriks yaitu EFE Matrix, CPM Matrix, IFE Matrix.

Informasi yang berasal dari ketiga matriks ini memberikan informasi dasar untuk matriks di tahap pencocokan dan tahap keputusan dalam merumuskan strategi.

\section{Tahap 2 :}

Terdiri dari Matriks SWOT, Matriks SPACE, Matriks BCG, dan Matriks IE. Alat ini bersandar pada informasi yang diturunkan dari tahap input untuk mencocokkan peluang dan ancaman eksternal dan dengan kekuatan dan kelemahan internal.

Tahap 3 :

Hanya terdiri dari 1 matriks yaitu QSPM. QSPM ini menggunakan input informasi dari Tahap 1 dan hasil pencocokan dari analisis Tahap 2, memberikan informasi yang dibutuhkan untuk membuat QSPM. QSPM adalah alat yang memungkinkan penyusun strategi untuk mengevaluasi alternatif strategi secara objektif, berdasarkan faktor keberhasilan kunci internal dan eksternal yang telah diidentifikasi sebelumnya.

\section{Rumusan Masalah}

Perumusan masalah dalam penelitian ini adalah :

1. Bagaimanakah kondisi faktor-faktor eksternal yang meliputi peluang (opportunities) dan ancaman (threats) yang ada di kawasan wisata Telaga Ngebel ?

2. Bagaimanakah kondisi faktor-faktor internal yang meliputi kekuatan (strengths) dan kelemahan (weaknesses) yang ada di kawasan wisata Telaga Ngebel ?

3. Bagaimana strategi yang tepat untuk pengembangan kawasan wisata Telaga Ngebel menggunakan analisis SWOT ?

\section{III.METODE PENELITIAN}

\section{A. Obyek dan Lokasi Penelitian}

Obyek dalam penelitian ini adalah Kawasan Wisata Telaga Ngebel yaitu sebuah telaga alami yang berlokasi di Kecamatan Ngebel, terletak $24 \mathrm{Km}$ ke arah Timur Laut dari pusat Kota Ponorogo atau yang terkenal dengan nama Kota Reyog. Telaga Ngebel berada di lereng gunung Wilis dengan ketinggian 734 M (DPL). Luas permukaan Telaga Ngebel sekitar $1,5 \mathrm{Km}^{2}$ dan dikelilingi jalan sepanjang $5 \mathrm{Km}$ dengan suhu udara antara 20 - 26 derajat celcius, suhu dingin nan sejuk membuat pengunjung makin nyaman mengunjungi Telaga Ngebel.

Kawasan ini memiliki panorama alam yang menakjubkan dengan kondisi yang masih alami menyimpan sejuta potensi untuk digali. Selain Reyog, Telaga Ngebel merupakan salah satu andalan wisata yang dimiliki Kabupaten Ponorogo. Pemasok air bagi Telaga Ngebel terdiri dari berbagai sumber. Sumber air yang cukup deras berasal dari Kanal Santen.

Obyek wisata lain di sekitar wilayah Ngebel yang sangat mendukung potensi pengembangan Kawasan Wisata Telaga Ngebel antara lain : Air Terjun Toyomarto, Air Terjun Selorejo, Situs Sumber Dukun, Obyek Wisata Bale Batur, Perahu Nyi Latung, Situs Sumber Bethoro, Air Tiga Rasa, Sumber Air Panas, Kawah Padosan yaitu sumber air panas yang diyakini masyarakat sekitar bisa menyembuhkan beberapa penyakit kulit, Wisata Religi, Agrowisata Buah dan Sayur, Rescue \& Lifeguard, Negeri di 
Website : http://ekomaks.unmermadiun.ac.id/index.php/ekomaks

Awan, obyek foto di atas pohon, view telaga, Sumber Gas Bumi, Potensi Tambang Emas, tempat latihan SARGURILA (SAR Gunung, Rimba, Laut). Bagi pengunjung yang bermaksud untuk bermalam telah tersedia hotel, penginapan dan home stay.

Selain obyek wisata di atas, berbagai event wisata juga sangat mendukung potensi pengembangan kawasan wisata Telaga Ngebel, diantaranya meliputi : event budaya yaitu Tari-Tarian dan Pagelaran Reyog setiap 2 bulan, event budaya Grebeg Suro setiap tahun, Pameran Durian, Pameran Hasil Bumi dan lain-lain.

Gambar 2. Peta Wisata Telaga Ngebel

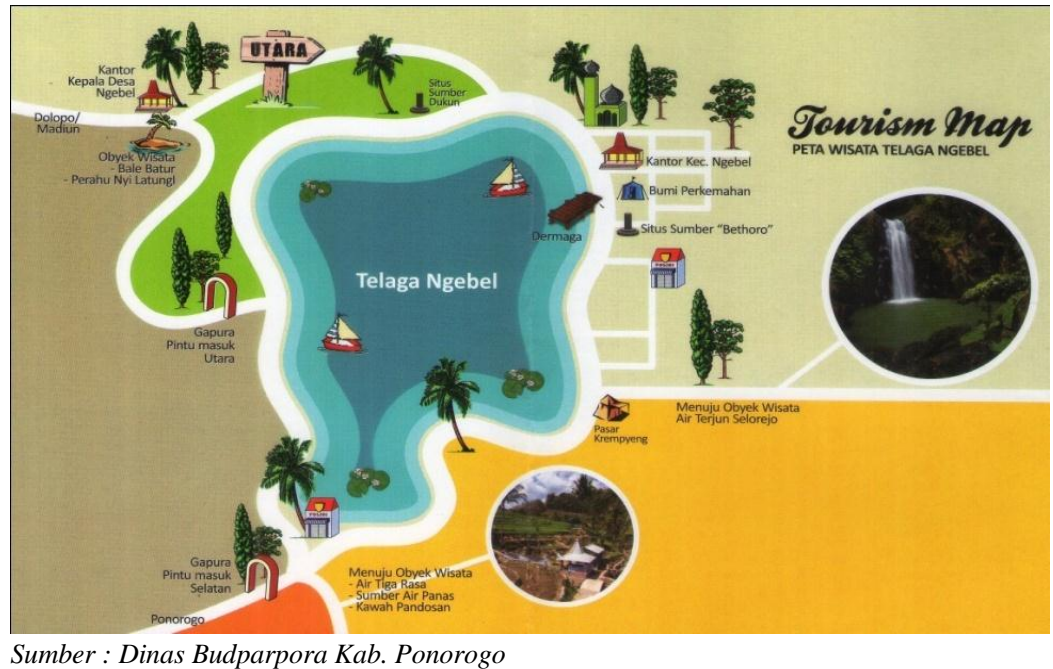

\section{B. Jenis dan Metode Pengumpulan Data}

Jenis data pada penelitian ini adalah data primer dan data sekunder. Data primer diperoleh dari masyarakat di kawasan wisata Telaga Ngebel. Sedangkan data sekunder diperoleh dari buku, undang-undang, jurnal, publikasi BPS serta artikel internet. Metode pengumpulan data melalui : kuesioner kepada masyarakat, wawancara dengan pengelola, tokoh masyarakat, pejabat dinas dikbudparpora dan aparat kecamatan, dokumentasi dan tinjauan pustaka. Untuk melengkapi hasil penelitian juga dilakukan pengamatan atau observasi langsung pada kawasan wisata Telaga Ngebel untuk mengetahui potensi wisata yang belum dimanfaatkan secara optimal oleh masyarakat sekitar dalam menunjang pengembangan kawasan wisata dan meningkatkan kesejahtraan.

\section{Metode Analisis}

\section{Analisis SWOT (Strengths, Weaknesses, Opportunities, Threats)}

Metode ini digunakan untuk mengetahui metode strategi pengembangan melalui analisis SWOT dengan cara menganalisis faktor-faktor eksternal (peluang dan ancaman) dan faktor-faktor internal (kekuatan dan kelemahan) dengan matriks EFE dan IFE. Matriks External Faktor Evaluation (EFE) digunakan untuk menganalisis faktor-faktor yang berupa peluang dan ancaman yang dihadapi. Data faktor eksternal dicari untuk menganalisis hal-hal yang berkaitan dengan persoalan ekonomi, budaya, sosial, lingkungan, demografi, politik, hukum, pemerintahan, teknologi, dan persaingan pasar. Matriks Internal Faktor Evaluation (IFE) digunakan untuk menganalisis faktor-faktor yang berupa kekuatan dan kelemahan yang dimiliki. Data faktor internal dicari untuk menganalisis hal-hal yang berkaitan dengan beberapa fungsional perusahaan, misalnya dari aspek manajemen, keuangan, sumber daya manusia, pemasaran , informasi, dan produksi.

\section{Matrik Faktor Strategi Eksternal}

Sebelum membuat matrik strategi eksternal, perlu diketahui terlebih dahulu faktor strategi eksternal (EFE). Dibawah ini adalah cara-cara penentuan Faktor Strategi Eksternal :

a. Susunlah dalam kolom 1daftar faktor-faktor utama yang mempunyai dampak penting pada kesuksesan atau kegagalan usaha yang terdiri berbagai peluang (opportunities) dan ancaman(threats).

b. Beri bobot masing-masing faktor dalam kolom 2. Jumlah seluruh bobot harus sebesar 1,0. Nilai bobot dicari dan dihitung berdasarkan rata-rata industrinya. Nilai bobot yang ditentukan adalah : - 0,20 atau 20\% : Kuat atau tinggi $-0,15$ atau $15 \%$ : Diatas rata-rata $-0,10$ atau $10 \%$ : Rata-rata $-0,05$ atau 5\% : Dibawah rata-rata $-0,00$ atau $0 \%$ : Tidak terpengaruh.

c. Hitung rating (dalam kolom 3) untuk masing-masing faktor dengan memberikan skala mulai dari 4 (sangat kuat) sampai dengan 1 (sangat lemah) berdasarkan pengaruh faktor tersebut terhadap kondisi perusahaan yang bersangkutan. Pemberian nilai rating untuk faktor peluang bersifat positif (peluang yang semakin besar diberi rating 
Website : http://ekomaks.unmermadiun.ac.id/index.php/ekomaks

+4 , tetapi jika peluangnya kecil, diberi rating +1 ). Pemberian nilai rating ancaman adalah kebalikannya. Misalnya jika nilai ancamannya sangat besar, ratingnya adalah 1. Sebaliknya, jika nilai ancamannya sedikit ratingnya 4. Rating ditentukan berdasarkan efektivitas strategi objek wisata Telaga Ngebel. Dengan demikian, nilainya didasarkan pada kondisi objek wisata tersebut.

d. Kalikan bobot pada kolom 2 dengan rating pada kolom 3, untuk memperoleh faktor pembobotan dalam kolom 4. Hasilnya berupa skor pembobotan untuk masing-masing faktor.

e. Gunakan kolom 5 untuk memberikan komentar atau catatan mengapa faktor-faktor tertentu dipilih dan bagaimana skor pembobotannya dihitung.

f. Jumlahkan skor pembobotan (pada kolom 4), untuk memperoleh total skor pembobotan bagi perusahaan yang bersangkutan. Nilai total ini menunjukkan bagaimana perusahaan tertentu bereaksi terhadap faktor-faktor strategis eksternalnya. Total skor ini dapat digunakan untuk membandingkan perusahaan lainnya dalam kelompok industri yang sama.

\section{Matrik Faktor Strategi Internal}

Setelah faktor-faktor strategis internal suatu perusahaan diidentifikasi, suatu tabel IFE disusun untuk merumuskan faktor-faktor strategis internal tersebut dalam kerangka kekuatan dan kelemahan perusahaan.

Tahapnya adalah :

a. Susunlah dalam kolom 1 yang terdiri dari faktor-faktor yang menjadi kekuatan serta kelemahan perusahaan.

b. Beri bobot masing-masing faktor dalam kolom 2. Faktor-faktor tersebut kemungkinan dapat memberikan dampak terhadap faktor strategis. (Semua bobot tersebut jumlahnya tidak boleh melebihi skor total 1,00)

c. Hitung rating (dalam kolom 3) untuk masing-masing faktor dengan memberikan skala mulai dari 4 (sangat kuat) sampai dengan 1 (sangat lemah) berdasarkan pengaruh faktor tersebut terhadap kondisi perusahaan yang bersangkutan. Variabel yang bersifat positif (semua variabel yang masuk kategori kekuatan) diberi nilai mulai dari +1 sampai dengan +4 (sangat baik) dengan membandingkannya dengan rata-rata industri atau dengan pesaing utama. Sedangkan variabel yang bersifat negatif, kebalikannya. Contohnya, jika kelemahan perusahaan besar sekali dibandingkan dengan rata-rata industri, nilainya adalah 1, sedangkan jika kelemahan perusahaan di bawah rata-rata industri, nilainya adalah 4. Rating mengacu pada kondisi kawasan wisata Telaga Ngebel, sedangkan bobot mengacu pada industri pariwisata di mana kawasan wisata Telaga Ngebel berada.

d. Kalikan bobot pada kolom 2 dengan rating pada kolom 3, untuk memperoleh faktor pembobotan dalam kolom 4. Hasilnya berupa skor pembobotan untuk masing-masing faktor yang nilainya bervariasi mulai dari 4 sampai dengan 1 .

e. Gunakan kolom 5 untuk memberikan komentar atau catatan mengapa faktor-faktor tertentu dipilih dan bagaimana skor pembobotannya dihitung.

f. Jumlahkan skor pembobotan (pada kolom 4), untuk memperoleh total skor pembobotan bagi perusahaan yang bersangkutan. Nilai total ini menunjukkan bagaimana perusahaan tertentu bereaksi terhadap faktor-faktor strategis internalnya. Total skor ini dapat digunakan untuk membandingkan perusahaan lainnya dalam kelompok industri yang sama.

4. Matriks SWOT

Menurut Freddy Rangkuti (2005), alat analisis yang dipakai untuk menyusun faktor-faktor strategis perusahaan adalah matrik SWOT. Matrik ini dapat menggambarkan secara jelas bagaimana peluang dan ancaman eksternal yang dihadapi perusahaan dapat disesuaikan dengan kekuatan dan kelemahan yang dimilikinya. Matrik ini dapat menghasilkan empat set kemungkinan alternatif strategis.

\begin{tabular}{|c|c|c|}
\hline$I F E$ & STRENGTHS (S) & WEAKNESSES (W) \\
\hline & $\begin{array}{c}\text { Faktor-Faktor } \\
\text { Kekuatan Internal }\end{array}$ & $\begin{array}{c}\text { Faktor-Faktor } \\
\text { Kelemahan Internal }\end{array}$ \\
\hline OPPORTUNITIES (O) & STRATEGI-SO & STRATEGI-WO \\
\hline $\begin{array}{c}\text { Faktor-Faktor } \\
\text { Peluang Eksternal }\end{array}$ & $\begin{array}{l}\text { Ciptakan strategi } \\
\text { yang menggunakan } \\
\text { kekuatan untuk } \\
\text { memanfaatkan peluang }\end{array}$ & $\begin{array}{l}\text { Ciptakan strategi yang } \\
\text { menggunakan kekuatan } \\
\text { untuk meminimalkan } \\
\text { kelemahan untuk meraih } \\
\text { peluang. }\end{array}$ \\
\hline
\end{tabular}


Website : http://ekomaks.unmermadiun.ac.id/index.php/ekomaks

\begin{tabular}{|c|l|l|}
\hline \multicolumn{1}{|c|}{ TREATHS $(\boldsymbol{T})$} & \multicolumn{1}{|c|}{ STRATEGI-ST } \\
\hline $\begin{array}{c}\text { Faktor-Faktor } \\
\text { Ancaman Eksternal }\end{array}$ & $\begin{array}{l}\text { Ciptakan strategi } \\
\text { yang menggunakan } \\
\text { kekuatan untuk } \\
\text { mengatasi ancaman }\end{array}$ & $\begin{array}{l}\text { Ciptakan strategi yang } \\
\text { meminimalkan } \\
\text { kelemahan untuk } \\
\text { menghindari ancaman }\end{array}$ \\
\hline
\end{tabular}

\section{Matriks Internal-Eksternal (IE)}

Menurut Freddy Rangkuti, Matriks IE didasari pada dua dimensi kunci yaitu total rata-rata tertimbang IFE pada sumbu $\mathrm{x}$ dan total rata-rata tertimbang EFE pada sumbu y untuk mendapatkan strategi yang tepat berdasarkan hasil matriks IFE dan matriks EFE.

\begin{tabular}{|c|c|c|c|c|}
\hline & \multicolumn{4}{|c|}{$\begin{array}{l}\text { Gambar 4. Matriks Internal - Eksternal (IE) } \\
\text { TOTAL RATA-RATA TERTIMBANG IFE }\end{array}$} \\
\hline & & $\begin{array}{l}\text { Kuat } \\
3,0-4,0\end{array}$ & $\begin{array}{l}\text { Rata-Rata } \\
2,0-2,99\end{array}$ & $\begin{array}{l}\text { Lemah } \\
1,0-1,99\end{array}$ \\
\hline & 4,0 & 3,0 & 2,0 & 1,0 \\
\hline $\begin{array}{l}\text { Tinggi } \\
\mathbf{3 , 0}-\mathbf{4 , 0}\end{array}$ & & I & II & III \\
\hline $\begin{array}{l}\text { Menengah } \\
2,0-2,99\end{array}$ & & IV & $\mathbf{V}$ & VI \\
\hline $\begin{array}{c}\text { Rendah } \\
1,0-1,99\end{array}$ & $\mathbf{3 , 0}$ & VII & VIII & IX \\
\hline
\end{tabular}

\section{Penjelasan Matriks Internal-Eksternal (IE) :}

Matriks IE dapat dibagi menjadi tiga daerah utama yang memiliki implikasi strategi berbeda, yaitu sebagai berikut :

1. Rekomendasi untuk divisi yang masuk dalam sel I, II, IV dapat digambarkan sebagai “tumbuh dan kembangkan". Strategi intensif (penetrasi pasar, pengembangan pasar, dan pengembangan produk) atau strategi integratif (intregasi ke belakang, integrasi ke depan, dan integrasi horizontal) paling sesuai untuk divisi-divisi ini.

2. Divisi yang masuk dalam sel III, V, VII dapat dikelola dengan cara terbaik dengan strategi "jaga dan pertahankan" ; penetrasi pasar dan pengembangan produk adalah dua strategi yang umum digunakan untuk divisi tipe ini.

3. Rekomendasi yang umum diberikan untuk divisi yang masuk dalam sel VI, VIII, dan IX adalah "tuai atau divestasi", organisasi yang berhasil mampu mencapai portofolio bisnis yang diposisikan dalam atau sekitar sel I dalam matriks IE.

\section{IV.HASIL DAN PEMBAHASAN}

\section{A. Matriks External Factor Evaluation (EFE)}

Setelah faktor-faktor strategi eksternal yang terdiri dari peluang (opportunities) dan ancaman (threats) teridentifikasi, maka faktor-faktor tersebut dimasukkan kedalam Matriks EFE sebagaimana tertera pada Tabel 1. 
Website : http://ekomaks.unmermadiun.ac.id/index.php/ekomaks

Tabel 1. Matriks External Factor Evaluation (EFE)

\begin{tabular}{|c|c|c|c|}
\hline $\begin{array}{c}\text { Faktor-Faktor Strategi Eksternal } \\
\text { (1) }\end{array}$ & $\begin{array}{c}\text { Bobot } \\
\text { (2) }\end{array}$ & $\begin{array}{l}\text { Penilaian } \\
\text { (3) }\end{array}$ & $\begin{array}{l}\text { Nilai Akhir } \\
\text { (2) } \times \text { (3) }\end{array}$ \\
\hline $\begin{array}{l}\text { PELUANG } \\
\text { 1. Sektor pariwisata semakin berkembang dan semakin } \\
\text { diminati. } \\
\text { 2. Pertumbuhan ekonomi daerah meningkat } \\
\text { 3. Jumlah penduduk semakin meningkat } \\
\text { 4. Daya tarik budaya dan kesenian lokal/ nasional } \\
\text { 5. Kemajuan teknologi sangat mendukung } \\
\text { 6. Sikap dan persepsi positip masyarakat }\end{array}$ & $\begin{array}{c}12 \% \\
10 \% \\
8 \% \\
7 \% \\
8 \% \\
5 \%\end{array}$ & $\begin{array}{l}4 \\
3 \\
4 \\
3 \\
4 \\
2\end{array}$ & $\begin{array}{l}0,48 \\
0,30 \\
0,32 \\
0,21 \\
0,32 \\
0,10 \\
\end{array}$ \\
\hline $\begin{array}{l}\text { ANCAMAN } \\
\text { a. Infrastruktur/ kondisi jalan yang tidak memadai } \\
\text { b. Kurangnya alat transportasi umum } \\
\text { c. Persaingan antar obyek wisata } \\
\text { d. Investor besar belum tertarik menanamkan investasi } \\
\text { e. Terjadinya bencana/gangguan alam } \\
\text { f. Belum maksimalnya dukungan Pemerintah Daerah (dalam } \\
\text { sarana prasarana) }\end{array}$ & $\begin{array}{c}12 \% \\
10 \% \\
7 \% \\
10 \% \\
5 \% \\
6 \%\end{array}$ & $\begin{array}{l}1 \\
2 \\
2 \\
2 \\
3 \\
3\end{array}$ & $\begin{array}{l}0,12 \\
0,20 \\
0,14 \\
0,20 \\
0,15 \\
0,18\end{array}$ \\
\hline Total $E F E$ & $100 \%$ & & 2,72 \\
\hline
\end{tabular}

Hasil matrik di atas menunjukkan bahwa nilai EFE (External Factors Evaluation) sebesar 2,72 yang berarti bahwa faktor eksternal kawasan wisata Telaga Ngebel mengarah pada banyaknya peluang namun tidak lepas dari ancaman eksternal.

\section{B. Matriks Internal Factor Evaluation (IFE)}

Setelah faktor-faktor strategi internal yang terdiri dari kekuatan (Strengths) dan kelemahan (Weaknesses) teridentifikasi, maka faktor-faktor tersebut dimasukkan kedalam Matriks IFE sebagaimana tertera dibawah ini.

Tabel 2. Matriks Internal Factor Evaluation (IFE)

\begin{tabular}{|l|c|c|c|}
\hline \multicolumn{1}{|c|}{$\begin{array}{c}\text { Faktor-Faktor Strategi Internal } \\
(\mathbf{1})\end{array}$} & $\begin{array}{c}\text { Bobot } \\
(\mathbf{2})\end{array}$ & $\begin{array}{c}\text { Penilaian } \\
(\mathbf{3})\end{array}$ & $\begin{array}{c}\text { Nilai Akhir } \\
(\mathbf{2}) \mathbf{x}(\mathbf{3})\end{array}$ \\
\hline - KEKUATAN & & & \\
a. Pemandangan alam yang indah, sejuk dan nyaman & $15 \%$ & 4 & 0,60 \\
b. Objek wisata yang menarik dan unik & $10 \%$ & 4 & 0,40 \\
c. Keramahan masyarakat sekitar & $5 \%$ & 3 & 0,15 \\
d. Dukungan obyek wisata di sekitarnya & $8 \%$ & 4 & 0,32 \\
e. Beragam atraksi wisata/ pagelaran seni dan budaya & $8 \%$ & 4 & 0,32 \\
f. Keterlibatan dan dukungan masyarakat besar & $5 \%$ & 3 & 0,15 \\
g. Lokasi dapat diakses dari beberapa daerah & $5 \%$ & 3 & 0,15 \\
\hline KELEMAHAN & & & \\
a. Fasilitas dan produk wisata belum lengkap & $10 \%$ & 2 & 0,20 \\
b. Promosi belum maksimal & $10 \%$ & 1 & 0,10 \\
c. Kurangnya toko souvenir & $6 \%$ & 2 & 0,12 \\
d. Akses/ parkir kendaraan besar belum memadai & $8 \%$ & 1 & 0,08 \\
e. Penerangan jalan pada malam hari masih minim & $5 \%$ & 2 & 0,10 \\
f. Pengelolaan sampah/ kebersihan belum memadai & $5 \%$ & 3 & 0,15 \\
\hline \multicolumn{1}{|c|}{ Total IFE } & $\mathbf{1 0 0} \%$ & & $\mathbf{2 , 8 4}$ \\
\hline
\end{tabular}

Hasil matrik di atas menunjukkan bahwa nilai IFE (Internal Factors Evaluation) sebesar 2,84 yang berarti bahwa kawasan wisata Telaga Ngebel memiliki posisi internal yang kuat.

\section{Matriks Internal-Eksternal (IE)}

Guna mendapatkan strategi yang tepat, setelah faktor-faktor strategi eksternal yang terdiri dari peluang (opportunities) dan ancaman (threats) dimasukkan kedalam Matriks EFE serta faktor-faktor strategi internal yang terdiri dari kekuatan (Strengths) dan kelemahan (Weaknesses) dimasukkan kedalam Matriks IFE, selanjutnya hasil nilai akhir Matriks EFE dan Matriks IFE, dimasukkan kedalam Matriks Internal - Eksternal (IE) sebagaimana tertera dibawah ini. 
Website : http://ekomaks.unmermadiun.ac.id/index.php/ekomaks

Gambar 5. Hasil Matriks Internal - Eksternal (IE)

TOTAL RATA-RATA TERTIMBANG IFE

Kuat Rata-Rata Lemah

$3,0-4,0 \quad 2,0-2,99 \quad 1,0-1,99$

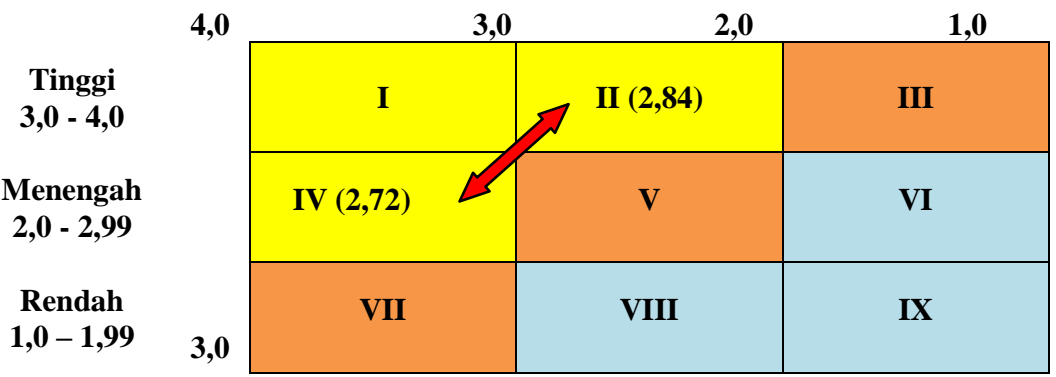

\section{Pemilihan Strategi}

Pemilihan strategi adalah proses pembuatan keputusan memilih diantara alternatif strategi dan variasi strategi yang dipertimbangkan dapat dipakai dan diterapkan untuk mencapai tujuan dengan cara-cara yang paling baik.

Berdasarkan matrik SWOT serta matrik Internal dan External (IE), maka alternatif strategi yang dapat dipertimbangkan adalah strategi SO, strategi WO, strategi ST, dan strategi WT. Dengan total nilai yang diperoleh dari hasil matrik EFE (2,72) yaitu berada di Sel IV dan IFE $(2,84)$ yaitu masuk di Sel II, maka alternatif strategi yang dipilih untuk pengembangan kawasan wisata Telaga Ngebel adalah strategi SO (Strenght-Opportunity).

Strategi SO (Strenght-Opportunity) berarti pengembangan kawasan wisata Telaga Ngebel dilakukan dengan memanfaatkan sebesar-besarnya peluang yang ada dari faktor eksternal dan memanfaatkan serta meningkatkan kekuatan-kekuatan yang dimiliki kawasan wisata Telaga Ngebel.

Adapun makna dari pilihan Strategi SO (Strenght-Opportunity) adalah bahwa pengelola kawasan Wisata Telaga Ngebel sebaiknya memilih kelompok strategi "tumbuh dan kembangkan". Strategi SO ini dipilih dengan menggunakan kekuatan yang dimiliki untuk memanfaatkan peluang yang ada agar kawasan Wisata Telaga Ngebel tumbuh dan berkembang sebagaimana yang diharapkan. Strategi yang tepat untuk hal ini adalah strategi intensif seperti pengembangan produk khususnya produk wisata, pengembangan pasar, penetrasi pasar.

\section{Pengembangan produk (Product Development Strategy)}

Pengembangan produk yaitu strategi yang dijalankan untuk meningkatkan jumlah wisatawan dengan memperbaiki dan mengembangkan produk wisata yang ada saat ini.

\section{Melakukan pengembangan pasar (Market Development Strategy) dan penetrasi pasar (Market Penetration Strategy)}

Strategi ini dilakukan dengan meningkatkan jumlah wisatawan secara intensif dengan melakukan pengembangan pasar dan penetrasi pasar melalui perluasan wilayah dan pemanfaatan media promosi secara intensif.

\section{E. Implementasi Strategi}

Guna mengimplementasikan strategi yang telah dipilih sebagaimana tersebut di maka agar pengembangan produk, pengembangan pasar dan penetrasi pasar dapat berjalan efektif, pihak pengelola kawasan Wisata Telaga Ngebel perlu melakukan hal-hal sebagai berikut :

1. Mengembangkan produk wisata Telaga Ngebel dengan menyediakan dan memperbaiki infrastruktur jalan, baik jalan (akses) menuju lokasi telaga maupun jalan yang mengitari telaga. Hal ini mutlak dilakukan agar akses wisatawan dari berbagai 
Website : http://ekomaks.unmermadiun.ac.id/index.php/ekomaks

daerah lebih mudah untuk menuju ke lokasi wisata. Jalan lingkar wilis yang telah direncanakan sebelumnya harus segera direalisasikan dengan koordinasi antar pemerintah daerah yang ada di sekitarnya maupun koordinasi lintas kementerian. Pengembangan produk wisata, tanpa perbaikan infrastruktur tidak akan membawa hasil yang optimal.

2. Pengembangan produk wisata di kawasan wisata Telaga Ngebel juga perlu dilakukan dengan penanganan kebersihan/ sampah yang efektif, serta menyediakan penerangan jangan terutama di malam hari.

3. Mengembangkan produk wisata dengan memperbanyak produk-produk wisata yang lain, seperti penyediaan Kuda untuk rekreasi keluarga, penyediaan kawasan toko souvenir dan pusat perbelanjaan kerajinan dan makanan khas daerah, penyediaan kolam renang, waterboom, penyediaan speed boat, penginapan dan rumah makan yang lebih bagus, senantiasa meningkatkan pagelaran seni dan budaya yang dapat menyedot perhatian wisatawan baik secara rutin maupun pada eveneven tertentu.

4. Pengembangan dan penetrasi pasar dapat dilakukan dengan melakukan promosi secara sistematis dan berkelanjutan. Dengan kemajuan teknologi di bidang informasi dan komunikasi, hendaknya hal tersebut dimanfaatkan semaksimal mungkin. Promosi melalui internet harus diimbangi dengan personil yang ahli dibidang IT yang setiap saat dapat meng-update berbagai informasi yang terkait dengan kawasan wisata Telaga Ngebel. Promosi juga dikembangkan dengan melakukan kerjasama dengan berbagai pihak, diantaranya bekerja sama dengan perusahaan Tour and Travel. Kerjasama juga dapat dilakukan dengan para investor, kantor-kantor, perusahaan dengan penyediaan paket-paket wisata yang menarik dan terjangkau, misalnya untuk kegiatan outbound, corporate gathering, camping, team building, fun refreshing, pelatihan, seminar, kegiatan olah raga dan lain-lain.

\section{KESIMPULAN DAN REKOMENDASI}

\section{A. Kesimpulan}

Berdasarkan hasil analisis dan pembahasan, maka dapat ditarik beberapa kesimpulan sebagai berikut :

1. Hasil matriks External Factor Evaluation (EFE) menunjukkan bahwa nilai EFE sebesar 2,72 yang berarti bahwa faktor eksternal yang dimiliki kawasan wisata Telaga Ngebel mengindikasikan adanya peluang yang sangat besar untuk mengembangkan kawasan wisata tersebut.

2. Hasil matriks Internal Factor Evaluation (IFE) menunjukkan bahwa nilai IFE sebesar 2,84 yang berarti bahwa kawasan wisata Telaga Ngebel memiliki faktor kekuatan internal yang besar.

3. Berdasarkan analisis SWOT dan perpaduan matrik SWOT dengan matrik Internal dan Eksternal (IE), maka alternatif strategi yang tepat guna mengembangkan kawasan wisata Telaga Ngebel adalah Strategi SO (Strenght-Opportunity) yaitu suatu strategi yang dipilih dengan menggunakan kekuatan yang dimiliki untuk memanfaatkan peluang yang ada agar kawasan Wisata Telaga Ngebel tumbuh dan berkembang.

4. Strategi SO dilakukan melalui penerapan strategi pengembangan produk wisata, pengembangan pasar dan penetrasi pasar.

5. Implementasi strategi yang perlu dilakukan diantaranya membuat kebijakan perbaikan infrastruktur jalan, mengembangkan produk wisata, meningkatkan promosi, menyediakan area toko souvenir, kerajinan dan makanan, menyediakan penerangan jalan, memperbaiki penanganan kebersihan dan sampah serta melakukan kerjasama dengan berbagai pihak termasuk para investor.

\section{B. REKOMENDASI}

Berdasarkan hasil penelitian yang dilakukan, maka dapat dikemukakan beberapa saran sebagai berikut :

1. Dengan peluang-peluang emas serta kekuatan-kekuatan yang dimiliki kawasan wisata Telaga Ngebel, Pemerintah Kabupaten Ponorogo beserta jajaran terkait sebaiknya lebih serius dan fokus untuk memanfaatkan peluang dan kekuatan yang ada untuk mempercepat pengembangan kawasan wisata tersebut menggunakan strategi "tumbuh dan kembangkan". Hal ini mengingat bahwa kawasan wisata Telaga Ngebel merupakan andalan sektor pariwisata Kabupaten Ponorogo bahkan diharapkan dapat menjadi daerah wisata unggulan di Jawa Timur.

2. Guna menumbuhkembangkan kawasan wisata Telaga Ngebel beberapa strategi perlu dirumuskan, misalnya misalnya strategi pengembangan produk wisata, strategi pengembangan pasar dan strategi penetrasi pasar.

3. Beberapa permasalahan penting seperti infrastruktur jalan, sarana parkir, kebersihan lingkungan, penerangan jalan, sarana dan prasarana transportasi sangat mendesak untuk segera mendapatkan solusi.

\section{VI.DAFTAR PUSTAKA}

Badan Pusat Statistik Kabupaten Ponorogo. 2017. Katalog. Kabupaten Ponorogo Dalam Angka 2017.@ B P S Ka bu p a te n P o n o r o g o .

Badan Pusat Statistik Kabupaten Ponorogo. 2017. Katalog. Statistik Daerah Kabupaten Ponorogo 2017.@ B P S K a b u p a t e n P o n o r o g o.

Dinas Kebudayaan dan Pariwisata Provinsi Jawa Timur. 2016. Brosur. Ayo Dolan Menyang Ponorogo. Ethnic Art of Java. Ponorogo.

Dinas Kebudayaan Pariwisata Pemuda dan Olahraga Kabupaten Ponorogo.2016. Brosur. Telaga Ngebel : The Hidden Treasures. Ethnic Art of Java. Ponorogo.

Ilyas, Muhammad. 2009. Strategi Pengembangan Pariwisata Kepulauan Togean di Kabupaten Tojo Una-Una. Tesis. Makassar: Program Studi Perencanaan Pengembangan Wilayah. Program Pascasarjana Universitas Hasanuddin.

Imron, Muhammad.2017. Prosiding Seminar Nasional Hasil Penelitian Tahun 2017. Analisis Persepsi Dan Sikap Masyarakat Terhadap Pengembangan Kawasan Wisata Telaga Ngebel Di Kabupaten Ponorogo.LPPM Unmer Madiun.

Katadata.2018. News and Research : Berapa Jumlah Penduduk Indonesia. www.databoks.katadata.co.id/datapublish/2018/01/12/berapa-jumlah-pendudukindonesia 
Website : http://ekomaks.unmermadiun.ac.id/index.php/ekomaks

[diakses pada tanggal 4 Pebruari 2018 jam 21:01]

Kotler, Philip \& Kevin Lane Keller. 2011. Marketing Management. 14 th Edition. New Jersey: Prentice Hall.

Pearce II, John A. dan Robinson Richard B.Jr. 2008. Manajemen Strategis 10. Salemba Empat : Jakarta.

Prasmul Tourism. 2017. Berita : Terus Berkembang Secara Stabil, Daya Tarik Pariwisata Indonesia Semakin Memukau Dunia. www.prasmultourism.com/2017/11/30/mengulas-daya-tarik-pariwisata-indonesia [diakses pada tanggal 4 Pebruari 2018 jam 19:44]

Rangkuti, Freddy. 2004. Analisis SWOT Teknik Membedah Kasus Bisnis. PT. Gramedia Pustaka Utama, Jakarta.

Sumarwoto, J. 1990. Pengembangan Agrowisata: Potensi dan Prospek. Seminar Nasional: Pembangunan Pertanian \& Pedesaan Sumatera. Berastagi, 5-8 Maret.

Republik Indonesia. 2007. Undang-undang Nomor 26 Tahun 2007 Tentang Penataan Ruang. Sekretariat Negara. Jakarta. 